\section{Role of Volume in the Regulation of Vasopressin Secretion during Pregnancy in the Rat}

\author{
William M. Barron, Barbara A. Stamoutsos, \\ and Marshall D. Lindheimer \\ Departments of Obstetrics and Gynecology, Medicine and \\ Pathology, the Pritzker School of Medicine, University \\ of Chicago, Illinois 60637
}

bstract. We previously observed that osmoregulation and the osmotic threshold for antidiuretic hormone secretion were altered during pregnancy in SpragueDawley rats and the present study evaluated the influence of volume on arginine vasopressin (AVP) release during gestation in this species. Basal plasma osmolality $\left(\mathbf{P}_{\text {osm }}\right)$ and intravascular volume were $297 \pm 3 \mathrm{mosmol} / \mathrm{kg}$ and $16.2 \pm 1.2 \mathrm{ml}$ in virgin animals compared with $290 \pm 2$ mosmol $/ \mathrm{kg}$ and $20.2 \pm 2.3 \mathrm{ml}$ in 14-d pregnant rats and $287 \pm 3 \mathrm{mosmol} / \mathrm{kg}$ and $25.2 \pm 2.3 \mathrm{ml}$ in 21 -d (near-term) pregnant rats $(P<0.001$, each pregnant group vs. virgin). Isosmotic volume depletion was produced by intraperitoneal polyethylene glycol. Volume decreased from 1 to $26 \%$ and blood pressure remained stable during decrements as high as $16 \%$. Plasma AVP $\left(P_{A V P}\right)$ did not rise significantly in either group of pregnant animals or virgin controls until blood volume depletion reached 6-7\%, after which levels rose in a similar exponential manner in virgin, 14-d, and 21-d pregnant animals. In terms of absolute changes, however, $P_{\text {AVP }}$ in gravid rats started to increase when intravascular volume was still considerably greater than basal blood volume in the nonpregnant controls.

Other experiments, where $P_{\text {osm }}$ was increased by intraperitoneal hypertonic saline, reconfirmed that the osmotic threshold for AVP secretion was reduced $\simeq 10$ mosmol/kg during pregnancy and that AVP release was stimulated by increments in body tonicity as small as 1$2 \%$. In parallel studies, blood volume contraction and increases in $\mathrm{P}_{\text {osm }}$ were evoked by intraperitoneal polyethylene glycol dissolved in hypertonic saline and results

Dr. Barron is a recipient of a Clinical Investigator Award (NIH-HL01145). Address reprint requests to Dr. Lindheimer.

Received for publication 15 October 1982 and in revised form 22 November 1983.

J. Clin. Invest.

(c) The American Society for Clinical Investigation, Inc.

0021-9738/84/04/0923/10 \$1.00

Volume 73, April 1984, 923-932 compared with animals receiving intraperitoneal saline alone. Decrements in volume $(\simeq 7 \%)$, which alone would increase $P_{A V P}$ minimally, increased the sensitivity of the secretory response to changes in osmolality two- to threefold, an effect which was similar in virgin and gravid animals. Finally, restricting water intake of pregnant rats to that of virgins on days 16-20 of gestation led to suboptimal volume expansion, hypertonicity, and an exaggerated increase in $\mathbf{P}_{\mathrm{AVP}}$.

These results demonstrate that despite an intravascular space which at term is nearly twice that of virgin rats, pregnant animals secrete AVP in response to fractional volume depletion in a manner similar to nonpregnant controls; that is, the relationship between total blood volume and AVP secretion is altered during gestation such that the expanded blood volume is recognized as normal.

\section{Introduction}

Osmoregulation is altered during both human and rodent gestation $(1-3)$. For instance, plasma osmolality $\left(P_{\text {osm }}\right)^{1}$ is $5-10$ mosmol/kg lower in pregnant than in nongravid women, yet gravidas concentrate and dilute their urines appropriately when subjected to water loading or dehydration (3). We have described similar alterations during rodent gestation, noting that $P_{\text {osm }}$ and the osmotic threshold for arginine vasopressin (AVP) secretion are decreased $\simeq 10 \mathrm{mosmol} / \mathrm{kg}$ in Sprague-Dawley and Long Evans rats $(4,5)$. Mechanisms responsible for these changes are undefined, but could relate to a variety of humoral, volume, or hemodynamic alterations that accompany pregnancy. Thus far, however, we have been unable to demonstrate any roles for circulating estrogen, progesterone, or angiotensin II $(4,6)$. Volume homeostasis, another variable influencing AVP secretion $(7,8)$, is also altered during gestation. For instance, total blood volume increases during pregnancy, and this could conceivably suppress hormone release $(9,10)$. On the other hand, some suggest that "effective blood volume" is actually decreased in

1. Abbreviations used in this paper: AVP, arginine vasopressin; $\mathbf{P}_{\mathrm{AVP}}$, plasma arginine vasopressin; $P_{o s m}$, plasma osmolality; $P E G$, polyethylene glycol. 
pregnancy (11) and in the nonpregnant rat, intravascular volume deficits decrease the osmotic threshold for, and stimulate the secretion of, antidiuretic hormone (9). The present study was therefore designed to characterize the influence of intravascular volume depletion on AVP release in pregnant rats. One hypothesis tested was that if "effective blood volume" was indeed decreased in the pregnant animals, they should respond to further depletion in an exaggerated fashion. The results, however, demonstrated that despite an increased intravascular space, which at term is nearly twice the controls, pregnant rats secrete AVP in response to fractional isosmotic volume depletion in a manner similar to that of age-matched virgin animals. This meant that plasma levels of the hormone increased in the gravid rat when circulating volume was still considerably greater than that of the controls. Said otherwise, the volume-sensing AVP secretory mechanism is altered during pregnancy such that the increased intravascular volume is recognized as normal.

\section{Methods}

Experiments were performed on pregnant Sprague-Dawley rats and agematched virgin controls (Holtzman Animal Supplies, Madison, WI). Gravid animals, mated between 11 and $12 \mathrm{wk}$ of age, were studied in the morning either 14 or $21 \mathrm{~d}$ after sperm was observed in vaginal smears. The animals, housed in a facility with constant temperature and fixed 12-h light cycle, were allowed free access to standard chow and water until the start of each experiment.

Blood volume determination. Total blood volume was determined by the simultaneous measurement of plasma volume (Evans blue dye dilution) and erythrocyte mass ( ${ }^{51} \mathrm{Cr}$-tagged erythrocytes) using a modification of methods described by Belcher and Harriss (12) and Gresson and colleagues (13). Briefly, animals were anesthetized with intraperitoneal pentobarbital and a tracheostomy was performed. PE-50 cannulas were placed in the right jugular vein and left carotid artery and $1 \mathrm{ml}$ isotonic saline was infused to replace surgical losses. ${ }^{51} \mathrm{Cr}$-tagged erythrocytes suspended in $0.2 \mathrm{ml}$ isotonic phosphate buffer were then injected intravenously and after $5 \mathrm{~min}, 0.2 \mathrm{ml}$ of Evans blue dye solution (50 $\mathrm{mg} / \mathrm{ml}$ ) was infused into the jugular vein. 5 min later arterial blood was collected for determination of ${ }^{51} \mathrm{Cr}$-radioactivity and dye concentration (spectrophotometry at $605 \mathrm{~nm}$ ). Standard curves, constructed by dissolving known quantities of dye in plasma (a gravid donor utilized when reading pregnancy unknowns and virgin plasma for the controls), were linear and highly reproducible.

Isosmotic intravascular volume depletion. Isosmotic blood volume depletion was produced using a modification of methods described by Brenner and Berliner (14) as well as Dunn and colleagues (9). $2 \mathrm{ml} /$ $100 \mathrm{~g}$ body weight i.p. of one of the following solutions were given: $(a)$ polyethylene glycol (PEG) (Sigma Chemical Co., St. Louis, MO; $\simeq 3,250$ mol wt) $70-90 \mathrm{mg} / \mathrm{ml}$ in isotonic saline; (b) $100-250 \mathrm{mg} / \mathrm{ml}$ PEG in slightly hypotonic saline; ${ }^{2}$ or $(c)$ isotonic saline alone; and $2 \mathrm{~h}$ later rats

2. Use of PEG at concentrations of $100 \mathrm{mg} / \mathrm{ml}$ or greater in isotonic saline actually produced hypertonic volume contraction. $P_{\text {osm }}$ rose as much as 4-5 mosmol $/ \mathrm{kg}$ above that of control animals receiving intraperitoneal isotonic saline alone and the increments persisted after correcting for the increases in plasma urea, which also occurred during volume depletion. This increased $P_{\text {osm }}$ can be explained by the fact that the nonabsorbable PEG causes a more rapid flux of water than solute were killed by guillotine, care being taken to avoid squeezing the thorax (16). Blood issuing from the trunk was collected in chilled heparinized tubes; small portions were immediately drawn for microhematocrit determination and the remainder centrifuged at $4^{\circ} \mathrm{C}$. Osmolality was determined on separated plasma and the remaining sample stored at $-10^{\circ} \mathrm{C}$ until further use. Immediately after death, the abdomen of each animal was carefully opened and the quantity of peritoneal fluid determined by weighing the carcass before and after evacuation of fluid. In addition, the uterine contents of each pregnant animal were weighed and the number of pups recorded.

In a separate series of studies, PE-50 cannulas placed in the left carotid artery of ether-anesthetized 21-d gravid and virgin rats, were tunnelled subcutaneously and externalized at the nap of the neck. Animals were allowed to awaken and 3 or more hours later arterial pressure was determined using a Bell and Howell 4327 transducer (Bell and Howell, Inc., Chicago, IL) and a Beckman type $R$ Dynograph (Beckman Instruments, Inc., Irving, CA). Measurements were performed on unrestrained rats and were continued until stable values were achieved. This procedure was then repeated $2 \mathrm{~h}$ after the intraperitoneal injection of $150-200 \mathrm{mg} / \mathrm{ml}$ PEG in slightly hypotonic saline.

Effect of volume depletion on the osmotic stimulation of $A V P$ release. To evaluate the effects of gestation on the $\mathbf{P}_{\mathrm{AvP}}$ response to stimultaneous volume depletion and osmotic stimulation, mild to moderate volume depletion was produced while $\mathbf{P}_{\text {osm }}$ was altered by the intraperitoneal injection ( $2 \mathrm{ml} / 100 \mathrm{~g}$ body weight) of PEG at concentrations of 175 $350 \mathrm{mg} / \mathrm{ml}$ dissolved in saline, the tonicity of which varied from 285 to $1,200 \mathrm{mosmol} / \mathrm{kg}$. Control rats received saline of similar concentration containing no PEG. Animals, killed $30 \mathrm{~min}$ after injection, were handled as described for the isosmotic depletion protocol.

In another series of studies, both volume depletion and hypertonicity were produced in a more chronic manner. 16-day gravid animals and age-matched virgins were housed in individual metabolic cages. Partial fluid restriction was produced by limiting the pregnant animals' daily water intake to that consumed the day previously by the virgin controls. Both gravid and virgin rats were killed $5 \mathrm{~d}$ later.

\section{Radioimmunoassay}

AVP assay. Plasma for AVP determination was extracted by the acetonepetroleum ether method of Robertson et al. (17). With this technique, $1 \mathrm{ml}$ of plsama yields $0.7 \mathrm{ml}$ of extract and when extract is evaporated to dryness, recovery of added AVP is $69.8 \pm 6.3 \%(n=12)$. Thus, the $0.7 \mathrm{ml}$ of extract should theoretically contain $100 \%$ of the original AVP in terms of concentration. In our assay, recovery of ${ }^{125} \mathrm{I}$-AVP added to plasma is $99 \pm 7 \%(n=32)$, while that of "cold" AVP is $98 \pm 11 \%$ $(n=8)$ at $1 \mathrm{pg} / \mathrm{ml}, 94 \pm 5 \%(n=8)$ at $3 \mathrm{pg} / \mathrm{ml}, 100 \pm 7 \%(n=8)$ at 5 $\mathrm{pg} / \mathrm{ml}$, and $101 \pm 5 \%(n=10)$ at $10 \mathrm{pg} / \mathrm{ml}$. The assay buffer was $0.1 \mathrm{M}$ sodium phosphate at $\mathrm{pH} 7.6$ and contained $0.3 \%$ (wt/vol) $\mathrm{NaCl}, 0.1 \%$ bovine serum albumin (Pentex; Miles Laboratories, Inc., Elkhart, IN) and $0.1 \%$ sodium azide. Standard curves were prepared with a highly purified synthetic AVP of potency $400 \mathrm{U} / \mathrm{mg}$ (lot 770110 , Ferring, Arzneimittel GMBH, Wittland, Federal Republic of Germany) in quantities that ranged from 0.10 to $10 \mathrm{pg} /$ assay tube; characteristics of this standard have previously been described (18). The tracer, the specific activity and nonspecific binding of which averaged $>1,000 \mu \mathrm{Ci} / \mu \mathrm{g}$ and $<5 \%$, re-

into the peritoneum (15). We succeeded in producing isosmotic dehydration by dissolving the PEG $(100-200 \mathrm{mg} / \mathrm{ml})$ in saline, the tonicity of which averaged $\sim 20 \mathrm{mosmol} / \mathrm{kg}$ below that injected into the controls. Furthermore, the data were acceptable only if the experimental animal's $P_{\text {osm }}$ was within 1 SD of the mean of the control (nondepleted) group. 
spectively, was prepared by iodinating synthetic AVP with the chloramine T method (19). The antiserum, produced in our laboratory (by Dr. J. Dürr) by immunizing rabbits with synthetic AVP coupled to bovine serum albumin via the gluteraldehyde method, was utilized at a final assay dilution of $1: 3,000,000$. This antiserum has $<5 \%$ cross-reactivity with lysine vasopressin $(4.3 \%)$, arginine vasotocin $(3.3 \%)$, and oxytocin $(<0.01 \%) .200 \mu \mathrm{l}$ of sample extract or of standard dissolved in buffer plus $200 \mu \mathrm{l}$ of antiserum in buffer were incubated in triplicate for $72 \mathrm{~h}$ at $4^{\circ} \mathrm{C}$. Then $100 \mu l$ of tracer $(2,000 \mathrm{cpm})$ was added and the incubation continued for an additional $65 \mathrm{~h}$ at $4^{\circ} \mathrm{C}$ after which bound and free vasopressin were separated by the addition of $1 \mathrm{ml}$ of a charcoal suspension [0.08\% Dextran T70 (Pharmacia Chemicals, Uppsala, Sweden), $0.16 \%$ bovine gamma-globulin (Pentex Fraction II, Miles Laboratories, Inc., Elkhart, IN) and $0.42 \%$ charcoal (Carbon Declorizing Alkaline, Norit-A, Fischer Scientific, Fair Lawn, NJ) in $0.1 \mathrm{M}$ sodium phosphate buffer] followed by centrifugation for $1 \mathrm{~h}$ at 3,000 rpm. Sensitivity of this assay is $0.15 \mathrm{pg} /$ assay tube and the $50 \%$ displacement is $2 \mathrm{pg} /$ assay tube. Extracts of plasma from homozygous Brattleboro rats (which have no endogenous AVP) were used as controls in most assays and demonstrated no displacement. Interassay and intra-assay variabilities at 0.5 $\mathrm{pg} /$ assay tube were 6.7 and $2.5 \%$, respectively.

Aldosterone assay. Plasma aldosterone was measured by a commercial kit (Abbott Diagnostics, Diagnostic Products, North Chicago, IL). The antiserum is highly specific and has virtually no cross-reactivity with other steroids or lactones. We could detect no aldosterone activity in blood from adrenalectomized rats.

Plasma osmolality was determined in duplicate by freezing-point depression (Advanced Instrument Osmometer 3D II, Advanced Instruments, Inc., Needham Heights, MA) and plasma urea nitrogen was determined on a Beckman Urea Analyzer II (Beckman Instruments, Inc., Fullerton, CA). Hematocrits were measured with an Adams microhematocrit centrifuge and reader (Clay Adams, Inc., New York) and were then used to determine changes in blood volume using the formula: percent blood volume depletion $(\Delta \mathrm{BV})=1-\mathrm{hct}_{\mathrm{c}} / \mathrm{hct}_{\mathrm{e}} \times 100$, where hct $t_{c}$ represents the mean hematocrit of the control and hcte, the experimental group. Use of this formula requires two assumptions: $(a)$ that the tested animal's hematocrit was similar to the control group mean before experimental manipulation and $(b)$ that circulating erythrocyte mass remains constant. Both ${ }^{51} \mathrm{Cr}$ - and ${ }^{3} \mathrm{H}$-radioactivity were determined using a Packard well-type counter (Packard Instruments, Inc., Downers Grove, IL).

Statistical analyses of group means were performed using the $t$ test for unpaired samples. Linear and exponential regression equations were generated with a programmable calculator, Hewlett-Packard model 41C (Hewlett-Packard, Corvallis, OR) using the least squares method and analyzed for differences using BMDP statistical software (20). Significant increases in dependent variables were determined as follows: Data grouped in intervals of the independent variable were subjected to analysis of variance, which was followed by Bonferroni multiple comparisons tests. Both procedures were performed using BMDP software (20). In addition the regression equation was utilized to calculate the point on the abscissa at which the independent variable increased to a value 2 SD above the mean of the control group. A $P$-value $<0.05$ was considered significant. A Bonferroni corrected $P$ value was used where multiple comparisons were performed. All data are given as mean \pm SD.

\section{Results}

Studies were performed on 471 rats. Total body weight of 14-d gravid animals (average $11 \pm 2$ pups/litter) was $304 \pm 20 \mathrm{~g}$ $(n=55)$ compared with $358 \pm 24 \mathrm{~g}(n=168)$ (average $11 \pm 2$ pups/litter) in 21-d gravid rats and $260 \pm 13 \mathrm{~g}(n=170)$ in agematched virgin controls $(P<0.001$ each pregnant group vs. virgin). $P_{o s m}$, plasma sodium, and hematocrit were all significantly lower in gravid rats, the mean values of which were $290 \pm 2 \mathrm{mosmol} / \mathrm{kg}, 141 \pm 2 \mathrm{meq} / \mathrm{liter}$, and $38.7 \pm 1.4 \%$, respectively, on gestational day $14(n=11)$ and $287 \pm 3 \mathrm{mosmol} / \mathrm{kg}$, $139 \pm 2 \mathrm{meq} / \mathrm{liter}$, and $33.0 \pm 2.1 \%$ on gestational day $21(n=16)$ compared with $297 \pm 3 \mathrm{mosmol} / \mathrm{kg}, 144 \pm 2 \mathrm{meq} / \mathrm{liter}$, and $42.0 \pm 1.6 \%$ in virgin animals $(n=17)$. All values in pregnant rats were significantly different $(P<0.001)$ from those in virgin controls.

Blood volume determination. Preliminary studies were performed to determine if the kinetics of the markers used to measure plasma volume and erythrocyte mass were similar in 21-d pregnant and virgin animals. Intravascular mixing was complete $5 \mathrm{~min}$ postinjection for Evans blue dye in both gravid and control rats. Furthermore, escape of the dye from the circulation (expressed as a percentage of the 5-min postinjection value) did not differ during the first 10 min postinjection, but by $1 \mathrm{~h}$ the loss was greater for the pregnant compared with virgin rats (pregnant: $33.5 \%$ loss, virgin: $21.5 \%$ loss, $P<0.005$ ). In a similar manner, mixing of ${ }^{51} \mathrm{Cr}$-labeled erythrocytes was complete in gravid and virgin rats at $10 \mathrm{~min}$ and serial measurement of erythrocyte mass remained stable from $10 \mathrm{~min}$ through $1 \mathrm{~h}$ after marker injection in both groups of animals.

Table I summarizes the results of plasma volume and erythrocyte mass determinations in pregnant and virgin rats. Total intravascular volume was significantly greater $(P<0.001)$ in both pregnant groups compared with virgin controls. In the

Table I. Blood Volume in Virgin and Pregnant Rats

\begin{tabular}{|c|c|c|c|c|c|c|}
\hline & \multicolumn{2}{|c|}{ Virgin (21) } & \multicolumn{2}{|c|}{ 14-d pregnant (12) } & \multicolumn{2}{|c|}{ 21-d pregnant* (12) } \\
\hline & $m l$ & $\mathrm{ml} / 100 \mathrm{~g} b w$ & $m l$ & $\mathrm{ml} / 100 \mathrm{~g} b w \neq$ & $m l$ & $\mathrm{ml} / 100 \mathrm{~g} b w \neq$ \\
\hline Plasma volume & $10.2 \pm 0.9$ & $3.7 \pm 0.3$ & $14.3 \pm 2.0 \S$ & $4.8 \pm 0.5^{\prime \prime}$ & $18.2 \pm 2.2^{\prime \prime}$ & $6.6 \pm 0.7^{11}$ \\
\hline Erythrocyte volume & $5.9 \pm 0.4$ & $2.2 \pm 0.2$ & $5.9 \pm 0.5$ & $2.0 \pm 0.2^{\prime \prime}$ & $7.0 \pm 0.4^{\prime \prime}$ & $2.5 \pm 0.1^{11}$ \\
\hline Total blood volume & $16.2 \pm 1.2$ & $5.9 \pm 0.4$ & $20.2 \pm 2.3^{\prime \prime}$ & $6.8 \pm 0.6^{\prime \prime}$ & $25.2 \pm 2.3^{\prime \prime}$ & $9.1 \pm 0.8^{11}$ \\
\hline
\end{tabular}

Mean $\pm \mathrm{SD} ; n$ is given in parentheses; bw, body weight. * All volumes in $21-\mathrm{d}$ gravid rats are significantly greater $(P<0.001)$ than those in 14-d gravid animals. $\ddagger$ Nonconceptus body weight. $\S P<0.025$ vs. virgin controls. " $P<0.001$ vs. virgin controls. 
14-d gravid animals, this was due solely to expansion of plasma volume $(+26 \%)$, while the marked increase in total blood volume $(+54 \%)$ in near-term pregnant rats was due to increments in both plasma volume $(+74 \%)$ and erythrocyte mass $(+14 \%)$. All volumes were significantly greater $(P<0.001)$ in $21-\mathrm{d}$ compared with 14-d pregnant animals.

Effect of intraperitoneal PEG on volume, blood pressure, and vasopressin. In a series of preliminary studies we validated the methodology used by Dunn and colleagues (9) by ascertaining that intraperitoneally injected PEG is not found in the circulation in quantities sufficient to significantly alter plasma osmolality determination. Tritiated PEG (New England Nuclear, Boston, $\mathrm{MA}, \simeq 3,850 \mathrm{~mol} \mathrm{wt}$ ) was added to $2 \mathrm{ml} / 100 \mathrm{~g}$ body weight of a solution containing unlabeled PEG $(250 \mathrm{mg} / \mathrm{ml}$ in saline $)$ and injected intraperitoneally into $21-\mathrm{d}$ gravid and virgin rats; plasma radioactivity measured $2 \mathrm{~h}$ later was considered to represent intact PEG. In these experiments, where the amount of PEG used was equivalent to the maximum amount injected into any rat during the isotonic volume depletion studies, only $0.47 \pm 0.23$ $\mathrm{mM} /$ liter and $0.41 \pm 0.13 \mathrm{mM} /$ liter PEG were detected in the plasma of pregnant $(n=8)$ and virgin $(n=8)$ rats, respectively. Addition of similar amounts of unlabeled PEG to rat plasma had no detectable effect on osmolality.

The degree of intravascular volume depletion achieved with intraperitoneal PEG ranged from $<1$ to $26 \%$ and values in individual rats are shown in Fig. 1. The isosmotic nature of volume contraction in both pregnant and virgin animals is demonstrated by the fact that $P_{\text {osm }}$ (corrected for urea) was $290 \pm 3$ mosmol/ $\mathrm{kg}$ in depleted vs. $289 \pm 3 \mathrm{mosmol} / \mathrm{kg}$ in control virgins, $280 \pm 3$ mosmol $/ \mathrm{kg}$ in depleted vs. $280 \pm 3 \mathrm{mosmol} / \mathrm{kg}$ in control $14-\mathrm{d}$ gravid rats, and $278 \pm 3 \mathrm{mosmol} / \mathrm{kg}$ in depleted vs. $277 \pm 3$ mos$\mathrm{mol} / \mathrm{kg}$ in control $21-\mathrm{d}$ pregnant animals. In a separate group of rats in which blood pressure was monitored before and after intraperitoneal instillation of PEG, intravascular volume depletion averaged $9.9 \pm 3.5 \%$ (range: $3.8-16.4 \%, n=14$ ) in nearterm gravid and $12.0 \pm 3.8 \%$ (range: $6.5-22.1 \%, n=18$ ) in virgin animals. There was no significant fall in mean arterial pressure in either group at any level of volume depletion studied.

$\mathbf{P}_{\mathrm{AVP}}$ response to isosmotic volume depletion: Fig. 1 further demonstrates the plasma vasopressin $\left(\mathbf{P}_{\mathrm{AVP}}\right)$ response to increasing degrees of isosmotic blood volume depletion. Control $P_{A V P}$ in virgin, 14-d and 21-d pregnant rats was $1.9 \pm 1.1 \mathrm{pg} / \mathrm{ml}$ $(n=32), 1.6 \pm 0.8 \mathrm{pg} / \mathrm{ml}(n=11)$, and $2.3 \pm 1.1(n=16)$, respectively. No increase in $P_{A V P}$ was discernible in any group until volume depletion reached 6-7\%. Above this level virgin and pregnant animals demonstrated a similar exponential rise in $P_{A V P}$ levels with progressively greater decrements in blood volume as defined by the equations: $P_{A V P}=1.56 \mathrm{e}^{0.14 \Delta \mathrm{BV}}, r$ $=0.88$ for virgin animals, $\mathrm{P}_{\mathrm{AVP}}=1.54 \mathrm{e}^{0.12 \Delta \mathrm{BV}}, r=0.90$ for 14-d pregnant rats, and $\mathrm{P}_{\mathrm{AVP}}=1.87 \mathrm{e}^{0.12 \Delta \mathrm{BV}}, r=0.92$ for $21-\mathrm{d}$ pregnant rats, where $\Delta B V$ represents the percent decrease in blood volume.

Fig. 2 contains data relating $\mathbf{P}_{\mathrm{AVP}}$ to absolute intravascular volume $(\mathrm{ml} / 100 \mathrm{~g}$ nonconceptus body weight) in near-term
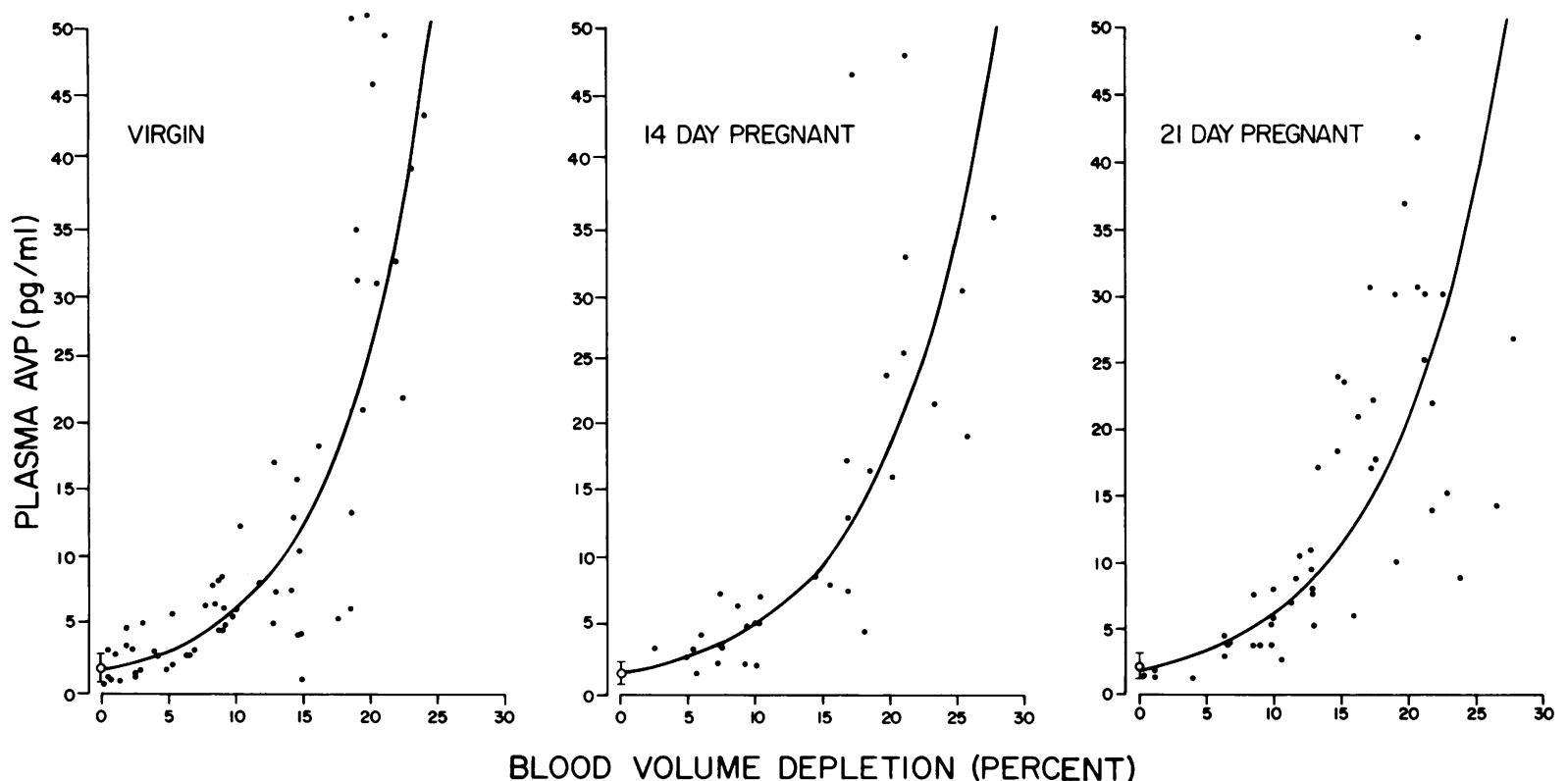

Figure 1. The relationship of plasma AVP to isosmotic decreases in blood volume. Experimental animals (virgin, $n=64$; 14-d pregnant, $n=33 ; 21-d$ pregnant, $n=49$ ) were injected intraperitoneally with PEG dissolved in isotonic or slightly hypotonic saline, while controls received isotonic saline alone. Control $P_{A V P}$ values are $1.9 \pm 1.1 \mathrm{pg} / \mathrm{ml}$ for virgin $(n=32), 1.6 \pm 0.8$ for $14-d$ gravid $(n=11)$, and $2.3 \pm 1.1$ for 21 -d gravid rats $(n=16)$. The regression equations relating changes in $P_{A V P}$ to percentage decrease in blood volume $(\triangle B V)$ are: virgin: $\mathrm{P}_{\mathrm{AVP}}=1.56 \mathrm{e}^{0.14 \Delta \mathrm{BV}}, r=0.88 ; 14-\mathrm{d}$ pregnant: $\mathrm{P}_{\mathrm{AVP}}=1.54 \mathrm{e}^{0.12 \Delta \mathrm{BV}}, r$ $=0.90 ; 21-\mathrm{d}$ pregnant: $\mathrm{P}_{\mathrm{AVP}}=1.87 \mathrm{e}^{0.12 \Delta \mathrm{BV}}, r=0.92$. 


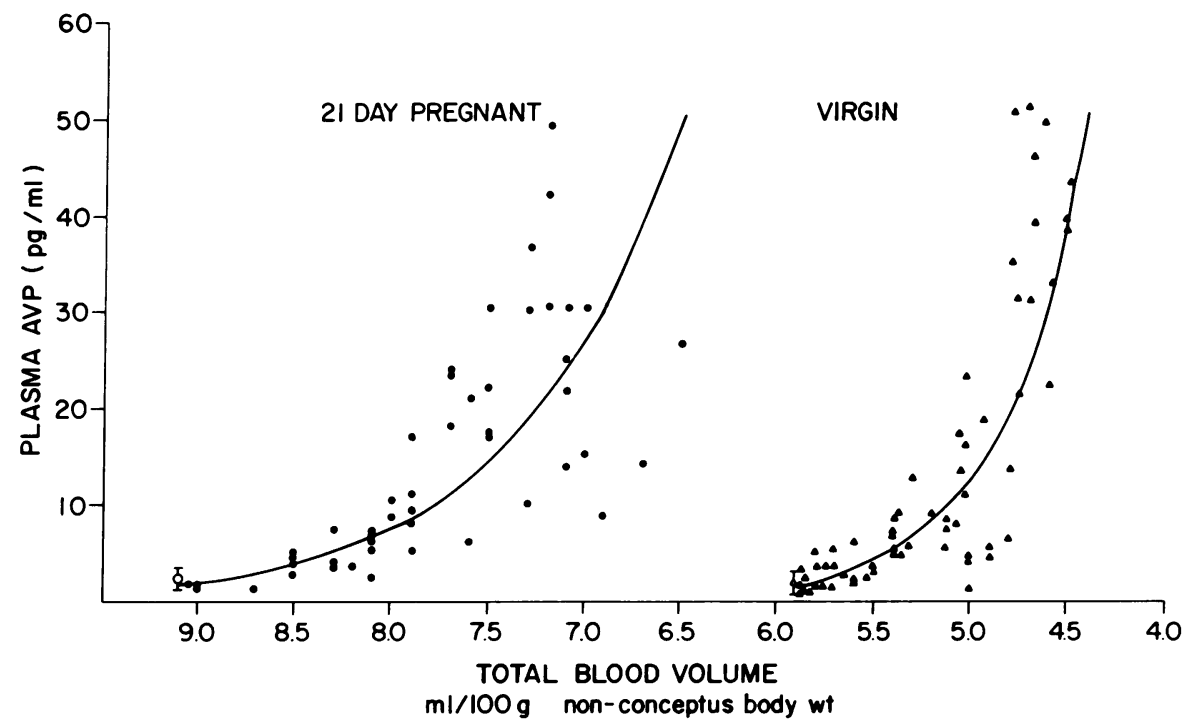

Figure 2. The relationship of $\mathbf{P}_{\mathrm{AvP}}$ to total blood volume in 21-d pregnant and virgin, control (open symbols) and volume depleted (closed symbols) rats. Note that the most severely depleted dams with the highest AVP values had volumes that were still greater than the virgin controls. pregnant and virgin rats. These data were derived by multiplying the percent depletion, calculated from changes in hematocrit, by each animal's estimated blood volume determined by using mean values derived from the experiments summarized in Table I. The results clearly demonstrate that the pregnant animal must lose a greater quantity of intravascular fluid than the virgin in order to evoke a given increment in $P_{A V P}$. Nevertheless, increases in AVP levels occur when the gravid rat has lost only $0.7 \mathrm{ml} /$ $100 \mathrm{~g}$ body weight, a point at which its total intravascular volume $(9.1-0.7=8.4 \mathrm{ml} / 100 \mathrm{~g}$ body weight $)$ is still substantially greater than that of the non-depleted virgin animals $(5.9 \mathrm{ml} / 100 \mathrm{~g}$ body weight). Furthermore, the pregnant rats with the greatest fractional depletion and $P_{A V P}$ levels $>30 \mathrm{pg} / \mathrm{ml}$ still had absolute volumes greater than that of the control virgins.

Effect of volume depletion on osmotic stimulation of AVP release. The intraperitoneal injection of hypertonic saline alone provoked increases in both $\mathbf{P}_{\text {osm }}$ and $\mathbf{P}_{A V P}$. Highly significant regression lines could be constructed for $21-\mathrm{d}$ gravid and virgin groups in which the $x$-intercept defined the apparent AVP secretory threshold which was $\simeq 11 \mathrm{mosmol} / \mathrm{kg}$ lower in pregnant compared with virgin animals. Table II contains values from three experiments performed over a period of $4 \mathrm{mo}$ and for further comparison, a fourth study previously published (4) and performed $2 \mathrm{yr}$ earlier. These data demonstrate that although correlation coefficients were high $(r=0.7-0.9)$ in each individual experiment, there was considerable variation in the slope of the regression line of both gravid (0.46-2.19) and virgin (0.64-2.34) rats. These variations, which occurred despite careful attempts to maintain similar experimental conditions such as age, weight, and housing conditions, in each study are similar to those reported by Dunn et al. (9) who observed a range of slopes from 0.8 to 1.9 in male Sprague-Dawley animals.

Fig. 3 and Table III summarize two experiments in which the effects of osmotic stimulation on AVP release were simultaneously studied in volume depleted and control rats. Both small $(\simeq 7 \%)$ and moderate $(\simeq 12 \%)$ blood volume depletion had profound effects of similar magnitude in $21-\mathrm{d}$ gravid and virgin animals on the osmotic release of AVP as evidenced by an increase of two- to threefold in the slopes of the regression lines for the volume depleted animals in each study.

Limitation of the pregnant animals' water intake during gestational days 16-20 led to hypertonicity, subnormal intra-

Table II. Relationship of Plasma AVP to Osmolality during Intraperitoneal Hypertonic Saline

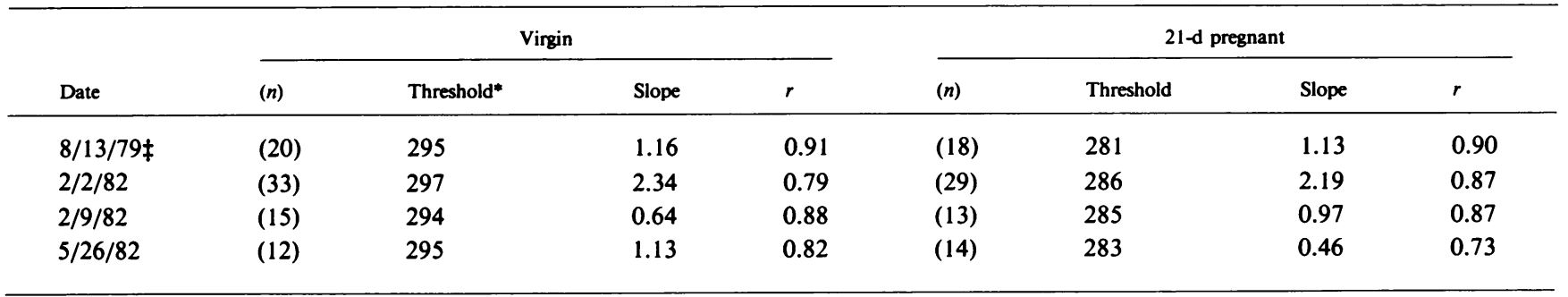

* Defined as $x$-axis intercept; all $r$ values are highly significant. $\ddagger$ From reference 4 . 

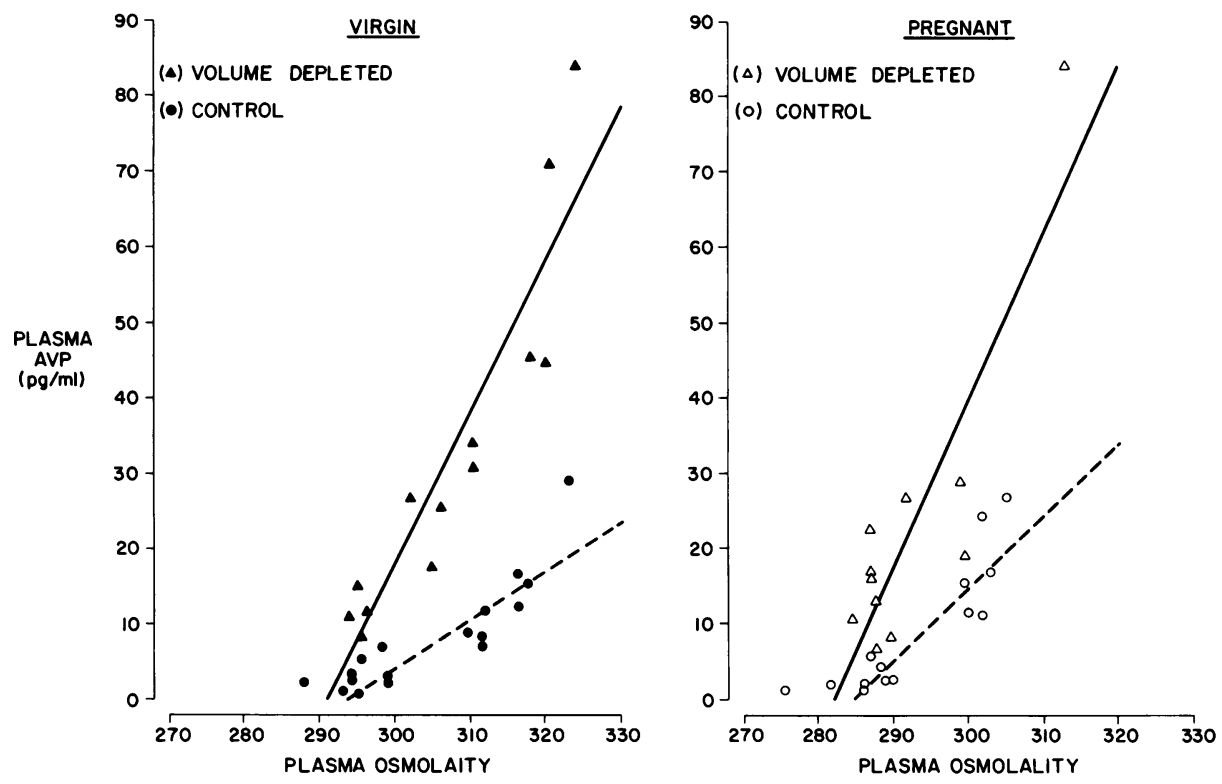

Figure 3. The effect of hypovolemia on the plasma AVP response to osmotic stimulation (plasma osmolality in mosmoles per kilogram). Experimental gravid $(11.8 \pm 2.8 \%$ volume depleted) and virgin $(12.4 \pm 2.1 \%$ volume depleted) rats (triangles-solid line) were injected intraperitoneally with PEG dissolved in isotonic or hypertonic $(500-1,200 \mathrm{mosmol} / \mathrm{kg})$ saline, while control animals (circles-dashed lines) received saline of similar tonicity without PEG.

vascular volume and a marked increase in $P_{A v P}$ (Table IV). $P_{\text {osm }}$, which is already minimal by day 15 of pregnancy $(21$, 22 ), increased in water-restricted gravid rats to that of the virgin while intravascular volume was $5.5 \%$ lower in water-deprived compared to control pregnant animals (hematocrit of waterdeprived rats was $34.8 \pm 2.1 \%$ vs. $33.0 \pm 2.1 \%$ in 21 -d gravid controls). The increase in $P_{A V P}$ from $2.7 \pm 0.3 \mathrm{pg} / \mathrm{ml}$ to $19 \pm 6 \mathrm{pg} /$ $\mathrm{ml}$ observed in these studies is consistent with the results of the above protocols wherein $\mathrm{P}_{\text {osm }}$ and blood volume were altered acutely.

\section{Discussion}

We previously reported that osmoregulation is altered during pregnancy in the Sprague-Dawley rat noting that $P_{\text {osm }}$ and the threshold $^{3}$ for antidiuretic hormone secretion decrease $\simeq 10$ mosmol/kg in near-term animals (4). The present data extend these observations and suggest that the volume-sensing AVP secretory mechanism is altered during pregnancy as well.

Volume, like osmolality, is an important determinant of AVP secretion. Reduction in extracellular fluid volume stimulates while intravascular volume expansion reduces AVP release $(7,10)$. Furthermore, in the rat, volume depletion may shift the osmotic threshold for AVP secretion to a lower $P_{\text {osm }}$ (9). Pregnancy in both humans and rodents is accompanied by sub-

3. Actually there is a debate as to whether or not the osmoreceptor truly exhibits threshold behavior or functions in a continuous manner (23-25). Certainly, there is a $P_{\text {osm }}$ under which $P_{A v p}$ is usually undetectable and urine osmolality minimal, and above which secretion is clearly stimulated. In the latter circumstance the AVP-osmolality relationship can be precisely defined by a linear equation and we have chosen to call the osmolar intercept of the regression equation relating $P_{A V P}$ to $P_{\text {osm }}$ the apparent secretory threshold. stantial increases in vascular volume (26), changes which in theory should suppress AVP release. However, it also has been suggested that despite absolute increments, "effective blood volume" is actually decreased during gestation (11), a circumstance akin to that seen in cirrhosis and congestive heart failure, two clinical situations in which nonosmotic stimulation of vasopressin secretion occurs (27-29). In favor of the latter view is that gravidity in humans is characterized by a marked stimulation of the renin-aldosterone system and a small decrement in mean arterial pressure (30). The present experiments were thus designed with the above views in mind, and one hypothesis considered was that if "effective blood volume" were in fact decreased the gravid rat would be hyper-responsive to further decrements in volume, responding with an earlier and steeper rise of $P_{A V P}$ levels when compared to control animals. Our findings, however, did not confirm this hypothesis. The $P_{A V P}$ responses to fractional decreases in blood volume were similar in 14-d pregnant, 21-d pregnant and virgin groups with little or no increase in secretion occurring until volume depletion had reached $6-7 \%$ and exponential rises noted with further fluid loss (Fig. 1). Also, since gravid animals had a larger intravascular space, a greater quantity of fluid loss was required to produce $\mathbf{P}_{\text {AVP }}$ levels similar to those of controls. Interestingly, however, the initial secretory response (thresholds) occurred when absolute intravascular volumes were still considerably greater than those of the nonpregnant rats (Fig. 2). Thus, the relationship between total blood volume and AVP release changes during pregnancy in such a manner that the increased intravascular volume is recognized as normal. Said otherwise, if the appropriate increase does not take place the effective volume will be sensed as decreased.

The relationship between $P_{A V P}$ and blood volume in gravid rats differs from that observed in acutely expanded nonpregnant 
Table III. Effect of Volume Depletion on Osmoreceptor Function

\begin{tabular}{|c|c|c|c|c|}
\hline Injectate & $n$ & Regression equation & $r$ & $\Delta \mathrm{BV}^{*}$ \\
\hline \multicolumn{5}{|l|}{ Virgin } \\
\hline Saline & 12 & $P_{A V P}=1.13\left(P_{o s m}-295\right)$ & 0.82 & \\
\hline Saline and PEG & 8 & $P_{A V P}=2.80\left(P_{\text {osm }}-296\right) \ddagger$ & 0.84 & $7 \pm 2 \%$ \\
\hline Saline & 15 & $P_{A V P}=0.64\left(P_{o s m}-294\right)$ & 0.88 & \\
\hline Saline and PEG & 13 & $P_{A V P}=2.02\left(P_{\text {osm }}-291\right) \ddagger$ & 0.92 & $12 \pm 2 \%$ \\
\hline \multicolumn{5}{|l|}{ 21-d pregnant } \\
\hline Saline & 14 & $P_{A V P}=0.46\left(P_{o s m}-283\right)$ & 0.73 & \\
\hline Saline and PEG & 10 & $P_{A V P}=1.01\left(P_{\text {osm }}-280\right) \ddagger$ & 0.88 & $7 \pm 2 \%$ \\
\hline Saline & 13 & $P_{A V P}=0.97\left(P_{\text {osm }}-285\right)$ & 0.89 & \\
\hline Saline and PEG & 11 & $P_{A V P}=2.22\left(P_{o s m}-282\right) \ddagger$ & 0.88 & $12 \pm 3 \%$ \\
\hline
\end{tabular}

* $\Delta \mathrm{BV}$, blood volume depletion. $¥$ Significantly different from saline-injected group.

dogs (31). In the latter species saline infusion calculated to increase blood volume $20 \%$ suppresses $P_{A V P}$. When the animals are then hemorrhaged in a manner which restores intravascular volume to euvolemic levels $P_{A v p}$ returns to base-line values. Whether the differences between these results and ours are due to pregnancy, chronic adaptation to 'hypervolemia' or a species difference remains to be determined.

Decrements in blood volume may decrease blood pressure and the latter change alone could be responsible for the observed increases in AVP secretion $(7,32)$. We therefore monitored intra-arterial pressure before and after intraperitoneal instillation of PEG. Pressures remained stable with volume depletion as great as $16 \%$, demonstrating that the increases in $\mathrm{P}_{\mathrm{AVP}}$ were primarily a function of the volume deficit per se.

Basal $\mathbf{P}_{\mathrm{AVP}}$ was similar in pregnant and control rats, and levels rose similarly as fractional volume deficits increased. Since

Table IV. Effects of $5 \mathrm{D}$ of Moderate Water Restriction in Pregnancy

\begin{tabular}{lccl}
\hline & Virgin (6) & $\begin{array}{c}\text { Pair-watered* } \\
\text { pregnant (6) }\end{array}$ & $P$ \\
\hline $\mathrm{H}_{2} \mathrm{O}$ intake $(\mathrm{ml} / 24 \mathrm{~h})$ & $35 \pm 3$ & $37 \pm 2$ & $\mathrm{NS}$ \\
Food intake $(\mathrm{g} / 24 \mathrm{~h})$ & $21 \pm 1$ & $23 \pm 3$ & $<0.05$ \\
Urine volume $(\mathrm{ml} / 24 \mathrm{~h})$ & $16 \pm 3$ & $13 \pm 2$ & $<0.05$ \\
$\mathrm{P}_{\text {osm }}(\mathrm{mosmol} / \mathrm{kg})$ & $298 \pm 2$ & $296 \pm 2$ & $\mathrm{NS}$ \\
$\mathrm{U}_{\text {osm }}(\mathrm{mosmol} / \mathrm{kg})$ & $1,855 \pm 272$ & $2,307 \pm 201$ & $<0.01$ \\
$\mathrm{P}_{\text {AVP }}(p g / \mathrm{ml})$ & $2.7 \pm 0.3$ & $19 \pm 6$ & $<0.001$ \\
$\mathrm{P}_{\text {aldosterone }}(p g / \mathrm{ml})$ & $235 \pm 120$ & $1,143 \pm 284$ & $<0.001$ \\
\hline
\end{tabular}

* The water intake of gravid rats was restricted to that consumed by virgin controls $1 \mathrm{~d}$ previously; $\boldsymbol{n}$ is given in parentheses. volume was always larger in near-term dams (Fig. 2) total circulating AVP was consistently greater in gravid compared to virgin rats at comparable levels of $\mathbf{P}_{\mathrm{AVP}}$. Metabolic clearance rates were not measured in these animals but if similar in the two groups and unaltered during volume depletion, gravid animals would have to secrete more hormone to achieve an identical increment in $\mathbf{P}_{\mathrm{AvP}}$.

In the second phase of these studies we analyzed the interaction of osmolality and volume on the control of AVP secretion. Interpretation of the data in Tables II and III and Fig. 3 requires review of previous observations concerning osmoregulation in the Sprague-Dawley strain. Dunn and colleagues (9) injected hypertonic saline intraperitoneally into male Sprague-Dawley rats and observed a positive and highly significant correlation between $P_{A V P}$ and $P_{o s m}$, the regression lines of which defined the apparent threshold for AVP secretion. They repeated these experiments seven times over many months and noted that although the threshold remained quite constant, the slope of the regression lines varied twofold, a phenomenon they were unable to explain. We too noted some variation in the slopes during our earlier studies in which hypertonicity was provoked by intraperitoneal saline once and by fluid deprivation on two other occasions (4). However, water restriction may evoke volume depletion as well as hypertonicity and in the present series the intraperitoneal saline studies were repeated three separate times. The results were consistent with those of Dunn and coworkers (9), the apparent threshold for AVP secretion changing little but the slopes varying considerably (virgin: 0.65-2.34; pregnant: $0.46-2.19$ ) from experiment to experiment.

Due to the variations described above, analysis of the interaction between osmotic and volume factors on AVP secretion in acute studies was limited to individual experiments where (a) intraperitoneal saline was injected into simultaneously studied 
control and depleted gravid and virgin animals and $(b)$ the magnitude of the volume deficit was similar in pregnant and nonpregnant rats. Two such experiments are summarized in Table III and Fig. 3. The data demonstrate that levels of intravascular volume depletion $(\simeq 7 \%)$ which alone would affect $P_{A v P}$ but minimally, increase the sensitivity of the secretory response to changes in osmolality two- to threefold, an effect that was similar in gravid and pregnant animals alike. One should note, however, that the enhanced secretory stimulus occurs in the gravid rat when $P_{\text {osm }}$ are still lower and absolute volume greater than in the nonpregnant state suggesting again that basal levels of $P_{\text {osm }}$ and vascular volume are recognized as normal. Dunn and colleagues (9) also noted that moderate volume depletion lowered the osmotic threshold for AVP secretion significantly albeit by only a few mosmol/ $\mathrm{kg}$. We too noted small decreases in the threshold which clearly could not explain the magnitude of the decrement seen in pregnancy.

The paired water studies (Table IV) were designed to affect both volume and tonicity in a more chronic manner than that used in acute experiments. After $5 \mathrm{~d}$ of limited water intake $P_{\text {osm }}$ in the gravid rats was equal to that in the virgins, while intravascular volume was $5.5 \%$ below that of free-drinking controls. The results are comparable to those of the acute studies in that the combination of hypertonicity and a decrement in volume (which alone should affect $P_{A V P}$ minimally) led to markedly increased levels of the hormone. These data are of further interest. In the PEG-hypertonic saline protocol, volume was actually decreased acutely while in the paired-water study the marked increment in intravascular volume that normally occurs during days $16-20$ (Table I) was presumably suppressed and it was suboptimal expansion (such as might occur in pregnant subjects who are sodium restricted or given diuretics), which apparently stimulated the AVP-secretory mechanism.

Our data provide little information on the mechanisms that alter the volume-sensing AVP secretory response in pregnancy, but one might speculate that it occurs at the level of the atria or venous capacitance system (the low pressure baroreceptors). Afferent impulses originating in the stretch receptors of the left atrium (possibly the right) or in the other parts of the cardiothoracic vasculature and transmitted to the brain via the vagus nerves are primarily responsible for the control of AVP release in response to volume changes of a magnitude which do not affect mean arterial pressure $(7,33,34)$. We are unaware of atrial, central venous, and/or pulmonary artery wedge pressure measurements in gravid rats but these values are unchanged in human pregnancy (35). Thus, there may be a primary vascular adaptation to the blood volume expansion (i.e., an increase in compliance) and since the increase is accommodated without increment in left atrial pressure, the central nervous system would interpret this new volume status as normal.

One might also speculate that vascular changes precede rather than accompany the volume expansion. This leads to a decrement in effective volume, nonosmotic stimulation of antidiuretic hormone release, and a decrease in the osmotic threshold for AVP secretion and thirst. The animal retains water in excess of sodium and $P_{\text {osm }}$ decreases, but once the enlarged vascular space is refilled, a new steady state is achieved, and maneuvers such as acute volume depletion with PEG produce results comparable to those in nongravid rats. The observations recorded during the paired water study are certainly compatible with such a view. However, this refilling of the dilated vascular space should also suppress the stimuli responsible for the decreased osmotic thresholds for thirst and AVP release as well as any nonosmotically mediated hormone secretion resulting in a return of $P_{o s m}$ and plasma sodium to or towards nongravid values. Since this does not occur, factors other than alterations in volume must be considered in the mechanism responsible for the hypoosmolality and decreased osmotic thresholds for thirst and AVP that are characteristic of rat gestation.

It should further be noted that the postulates presented here are based on observations that relate to days 14-21 of rat gestation, which is the period of greatest sodium retention and volume expansion (36). Volume-AVP relationships in early rat pregnancy, especially in the period preceding the decrease in $P_{\text {osm }}$ (before day 10) remain to be delineated.

Both extracellular (36-38) and intravascular $(21,39,40)$ volumes increase during pregnancy in the rat. Significant increments in the former have been noted by 11-12 d of pregnancy, levels then rising markedly during the final gestational week. Baylis (40) measured plasma volume in Munich-Wistar rats and noted small increases by day 6 and increments approaching $28 \%$ by day 12 , data consistent with the $27 \%$ increase in plasma volume observed in 14-day gravid animals in the present studies. Brown and Pike (39), studying near-term Sprague-Dawley rats, noted increases in plasma volume of $\sim 30 \%$. However, these authors sampled at $2 \mathrm{~min}$ and observed complete mixing of Evans blue dye at that time, a finding we could not confirm in preliminary studies. Thus, they probably underestimated the volume of distribution of the dye as their measurements are comparable to ours and those of Baylis (40) at midpregnancy before the accelerated expansion during the final week of gestation. Recently Atherton et al. (21) have reported an increase in plasma volume of $>50 \%$ (data derived from their Fig. $6 \mathrm{~A}$ ) by gestational day 20 while we observed an increment of $74 \%$ by day 21 . In addition, in the former study hematocrit had decreased $17 \%$ by day 20 while in ours the decrement was $27 \%$ $1 \mathrm{~d}$ later, a finding consonant with the rapid expansion of plasma volume occurring during the final week of gestation in this species $(21,39$, Table I).

Erythrocyte mass was also measured in the present experiments, demonstrating that these values also increase during gestation in Sprague-Dawley rats. The increments, however, were substantially less than for plasma volume, thus explaining the observed decreases in hematocrit from $42.0 \pm 1.6 \%$ in virgin animals to $38.7 \pm 1.4 \%$ in $14-\mathrm{d}$ gravid and to $33.0 \pm 2.1 \%$ in 21-d gravid rats. We are unaware of similar measurements in pregnant rodents, but it is of interest that these changes parallel those observed during human gestation (26). 
This study, which focused on the effects of volume and osmolality on antidiuretic hormone secretion in pregnancy, provides data that are also of interest in relation to previous reports that attempted to characterize the relative importance of these variables as stimuli of AVP release. In the earlier literature (reviewed in [7]) where bioassays were used there were discrepancies concerning the relative sensitivity of the secretory response to changes in either osmolality or volume. In 1973, Dunn et al. (9), using a highly specific and sensitive radioimmunoassay, were able to demonstrate increments in $P_{A V P}$ when $P_{\text {osm }}$ increased as little as $1-2 \%$, but volume depletion failed to evoke significant increases in hormone level until intravascular deficits reached $\simeq 7 \%$. Our observations in virgin animals are virtually identical to theirs and these relationships hold when extended to the pregnant rat.

In conclusion, these studies demonstrate that pregnant Sprague-Dawley rats secrete AVP in response to fractional decreases in blood volume in a manner similar to virgin animals although this occurs in the former at a markedly increased intravascular volume. This indicates that the relationship between total blood volume and AVP secretion is altered during gestation such that the expanded intravascular volume that accompanies the gravid state is recognized as normal. Furthermore, failure of volume to adequately expand will be sensed by the pregnant animal as decreased even when absolute volume exceeds that of the nonpregnant state. These findings complement previous observations from this laboratory demonstrating a resetting of the osmotic threshold for AVP release during pregnancy. Elucidation of the mechanisms whereby both osmotic and nonosmotic regulatory functions of the vasopressin system are reset during gestation will be the focus of future investigation.

\section{Acknowledgments}

We thank Ms. Theodora Stavrapoulos for excellent technical assistance; Dr. David Draper, Director of the Statistical Consultation Service at the University of Chicago, for invaluable help in analyzing the data, Ms. Joan Parks for skillful computer assistance; Drs. Adrian Katz and Gary Robertson for their critical comments; and Ms. Catherine Regovic for preparation of the manuscript.

This work was supported by generous grants from the National Institutes of Health (HD-5572 and T32 HL7237) and the Mother's Aid Research Fund of Lying-in Hospital.

\section{References}

1. Hytten, F. E. 1968. Physiological changes in early pregnancy. $J$. Obstet. Gynaecol. Br. Emp. 75:1193-1197.

2. Robertson, E. G., and G. A. Cheyne. 1972. Plasma biochemistry in relation to edema of pregnancy. J. Obstet. Gynaecol. Br. Emp. 79:769776.

3. Davison, J. M., M. B. Vallotton, and M. D. Lindheimer. 1981. Plasma osmolality and urinary concentration and dilution during and after pregnancy: evidence that lateral recumbency inhibits maximal urinary concentrating ability. Br. J. Obstet. Gynaecol. 88:472-479.

4. Durr, J. A., B. Stamoutsos, and M. D. Lindheimer. 1981. Os- moregulation during pregnancy in the rat. Evidence for resetting of the threshold for vasopressin secretion during gestation. J. Clin. Invest. 68:337-346.

5. Dürr, J. A., B. A. Stamoutsos, W. M. Barron, and M. D. Lindheimer. 1982. Osmoregulation in the pregnant Brattleboro rat. Ann. NY Acad. Sci. 394:481-490.

6. Dürr, J. A., B. A. Stamoutsos, and M. D. Lindheimer. 1981. Plasma osmolality $\left(\mathrm{P}_{\mathrm{osm}}\right)$ in pregnant rats in the absence of vasopressin (AVP) and during angiotensin blockade. Kidney Int. 19:238. (Abstr.)

7. Share, L. 1974. Blood pressure, blood volume and the release of vasopressin. Handb. Physiol. IV(Sect. 7, Pt. 1):243-255.

8. Schrier, R. W., T. Berl, and R. J. Anderson. 1979. Osmotic and nonosmotic control of vasopressin release. Am. J. Physiol. 236(4):F321F332.

9. Dunn, F. L., T. J. Brennan, A. E. Nelson, and G. L. Robertson. 1973. The role of blood osmolality and volume in regulating vasopressin secretion in the rat. J. Clin. Invest. 52:3212-3219.

10. Robertson, G. L., R. L. Shelton, and S. Athar. 1976. The osmoregulation of vasopressin. Kidney Int. 10:25-37.

11. Nolten, W. E., and E. N. Ehrlich. 1980. Sodium and mineralocorticoids in normal pregnancy. Kidney Int. 18:162-172.

12. Belcher, E. H., and E. B. Harris. 1957. Studies of plasma volume, red cell volume and total blood volume in young growing rats. J. Physiol. (Lond.). 139:64-78.

13. Gresson, C. R., D. L. Bird, and S. O. Simpson. 1973. Plasma volume, extracellular fluid volume and exchangeable sodium concentrations in the New Zealand strain of genetically hypertensive rat. Clin. Sci. (Lond.). 44:349-358.

14. Brenner, B. M., R. W. Berliner. 1969. Relationship between extracellular volume and fluid reabsorption by the rat nephron. $A m$. J. Physiol. 217(1):6-12.

15. Nolph, K. D., Z. J. Twardowski, R. P. Provich, and J. Rubin. 1979. Equilibration of peritoneal dialysis solutions during long dwell exchanges. J. Lab. Clin. Med. 93:246-256.

16. Husain, M. K., W. M. Manger, T. W. Rock, R. J. Weiss, and A. G. Frantz. 1979. Vasopressin release due to manual restraint in the rat: role of body compression and comparison with other stressful stimuli. Endocrinology. 104:641-644.

17. Robertson, G. L., E. R. Mahr, S. Athar, and T. Sinha. 1973. Development and clinical application of a new method for the radioimmunoassay of arginine vasopressin in human plasma. J. Clin. Invest. 52:2340-2352.

18. Mohring, J. 1978. Ferring workshop on the radioimmunoassay of vasopressin. Endokrinologie. 6:201-210.

19. Robertson, G. L., J. Roth, C. Beardwell, A. Klein, M. J. Peterson, and P. Gordon. 1973. Radioimmunoassay of vasopressin in man. In The Methods in Investigative and Diagnostic Endocrinology. S. A. Berson and R. Yalow, editors. North Holland Publishing Company, Amsterdam. IIA:656-668.

20. Dixon, W. J., M. B. Brown, L. Engleman, J. W. Frane, M. A. Hiu, R. I. Jenrich, and J. D. Tuporek. 1981. BMDP Statistical Software. University of California Press, Berkeley.

21. Atherton, J. C., J. M. Dark, H. O. Garland, M. R. A. Morgan, J. Pidgeon, and S. Soni. 1982. Changes in water and electrolyte balance, plasma volume and composition during pregnancy in the rat. J. Physiol. (Lond.). 330:81-93.

22. Barron, W. M., B. A. Stamoutsos, M. Langhofer, and M. D. Lindheimer. 1983. Effect of pseudopregnancy on plasma osmolality and vasopressin: comparison with normal pregnancy. Clin. Res. 31:729A. (Abstr.) 
23. Weitzman, R. E., and D. A. Fisher. 1977. Log linear relationship between plasma arginine vasopressin and plasma osmolality. Am. J. Physiol. 233:E37-E40.

24. Rodbard, D., and P. J. Munson. 1977. Editorial comment. Am. J. Physiol. 234:E340-341.

25. Robertson, G. L. 1980. Osmotic and hemodynamic control of vasopressin: functional and anatomical relationships. In Advances in Physiological Science. Kidney and Body Fluids. L. Takacs, editor. Pergamon Press, New York. 11:537-546.

26. Letsky, E. 1980. The haematological system. In Clinical Physiology in Obstetrics. F. Hytten and G. Chamberlain, editors. Blackwell Scientific Publications, Oxford. 43-78.

27. Bichet, D., V. Szatalowicz, C. Chaimovitz, and R. W. Schrier. 1982. Role of vasopressin in abnormal water excretion in cirrhotic patients. Ann. Int. Med. 96:413-417.

28. Szatalowicz, V., P. E. Arnold, C. Chaimovitz, D. Bichet, T. Berl, and R. W. Schrier. 1981. Radioimmunoassay of plasma arginine vasopressin in hyponatremic patients with congestive heart failure. $N$. Engl. J. Med. 305:263-266.

29. Riegger, G. A. J., G. Liebau, and K. Kochsiek. 1982. Antidiuretic hormone in congestive heart failure. Am. J. Med. 72:49-52.

30. Lindheimer, M. D., and A. I. Katz. 1981. The renal response to pregnancy. In The Kidney. B. M. Brenner and F. C. Rector, editors. Saunders Co., Philadelphia. Second ed. 1762-1815.

31. Shade, R. E., and L. Share. 1975. Volume control of plasma antidiuretic hormone concentration following acute blood volume expansion in the anesthetized dog. Endocrinology. 97:1048-1057.

32. Robertson, G. L. 1977. The regulation of vasopressin function in health and disease. Recent Prog. Horm. Res. 33:333-385.

33. Thames, M. D., and P. G. Schmid. 1979. Cardiopulmonary receptors with vagal afferents tonically inhibit $\mathrm{ADH}$ release in the dog. Am. J. Physiol. 237:H299-H304.

34. Menninger, R. 1981. Right atrial stretch decreases supraoptic neurosecretory activity and plasma vasopressin. Am. J. Physiol. 241:R44-49.

35. Rose, D. J., M. E. Bader, R. A. Bader, and E. Braunwald. 1956. Catheterization studies of cardiac hemodynamics in normal pregnant women with reference to left ventricular work. Am. J. Obstet. Gynecol. 72:233-244.

36. Alexander, E. A., S. Churchill, and H. H. Bengele. 1980. Renal hemodynamics and volume homeostasis during pregnancy in the rat. Kidney Int. 18:173-178.

37. Lindheimer, M. D., and A. I. Katz. 1971. Kidney function in the pregnant rat. J. Lab. Clin. Med. 78:633-641.

38. Atherton, J. C., and S. C. Pirie. 1981. The effect of pregnancy on glomerular filtration rate and salt and water reabsorption in the rat. J. Physiol. (Lond.). 319:153-164.

39. Brown, M. L., and R. L. Pike. 1960. Blood volume and serum protein in the deoxypridoxine-fed rat during pregnancy. J. Nutrition. 71:191-199.

40. Baylis, C. 1979. Effect of early pregnancy on glomerular filtration rate and plasma volume in the rat. Renal Physiol. 2:333-339. 